\title{
ANÁLISIS DE LOS ESTILOS DE ORIENTACIÓN EN EQUIPOS PSICOPEDAGÓGICOS
}

\author{
Ángel J. Lázaro Martínez \\ Universidad de La Rioja \\ Ma José Mudarra Sánchez \\ Universidad Complutense de Madrid
}

\begin{abstract}
RESUMEN. Tras reflexionar sobre las diferencias entre los paradigmas de investigación cuantitativos y cualitativos, entendemos que está superada la dicotomía entre ambos siendo precisa su complementariedad. Así, partiendo de un paradigma etnográfico y utilizando un diseño de estudio de casos, presentamos un estudio exploratorio sobre el "estilo" de Orientación de 4 Equipos Psicopedagógicos, esto es, la forma de especificación habitual de un modelo teórico de actividad orientadora, cruce de lo realizado, pretendido y conseguido en cada modelo de Orientación que fundamentamos mediante 3 dimensiones, (bases teóricas de la intervención, su estructura organizativa y desarrollo). Para descubrir los componentes básicos de dicha actividad orientadora realizamos un análisis de contenido mediante el programa de análisis textual SPAD-T .
\end{abstract}

ABSTRACT. After considering the differences between qualitative and quantitative research paradigms, we consider that the dichotomy between both is overcome and their complementary character is a must. Thus, taking an ethnographic paradigm as a starting point, and using a case study design, we present an exploratory study on the counseling "style" of 4 Psycho-pedagogical Teams, that is to say, the usual way of specification of a theoretical Counseling Model, a cross-check of the aim, the activity and the results in each counseling model that we base on 3 dimensions (theoretical basis of intervention, organizative structure and development). In order to find out the basic elements of this counseling activity, we carry out a content analysis via the text analysis program SPAD-T.

La propia naturaleza de la Orientación, un campo extraordinariamente amplio con límites difusos y de índole interdisciplinar, exige un tipo de investigación que combine cuidadosamente las reflexiones ontológicas y epistemológicas con el eminente carácter práctico de esta disciplina. Por ello, la investigación en este campo debería tender a la toma de decisiones sobre la acción dirigida al desarrollo y mejora, (podríamos decir la optimización), de individuos, situaciones, condiciones, procesos, equi- 
pos, etc., teniendo en cuenta que la Orientación es una actividad eminentemente formativa. Según nuestro criterio la investigación más adecuada en Orientación se aproxima a diseños más cualitativos.

No obstante, en la práctica encontramos dificultades para llevar a cabo este tipo de investigación. Señala el Prof. De la Universidad de Sevilla, Álvarez Rojo, (1994, 226), que:

“(...) la delimitación de las características de la investigación que se realiza en el campo de la Orientación se enfrenta a una considerable cantidad de trabajos cuya heterogeneidad es tal que el único nexo de unión entre ellos parece ser en muchos casos su inclusión en el mismo campo semántico: inclusión arbitraria (en cuanto prescrita o aceptada en virtud de dinámicas sociales específicas) debido a la dificultad (...) inherente al propio concepto de Orientación y a las circunstancias históricas que han caracterizado la institucionalización de la propia praxis orientadora (....."

Tal como definen Herr y Cramer por su parte, (1988), la investigación evaluativa, parece una opción metodológica ajustada al ámbito de la Orientación, pues tiene la virtud de combinar diversas estrategias y técnicas de investigación factorialista, subjetivas y cualitativas, etnográficas, etc. A pesar de ello, la realidad nos presenta el predomino de las metodologías cuantitativas, siendo la investigación de tipo cualitativo casi testimonial dada la escasez de investigaciones etnográficas y de estudio de casos.

\section{La investigación cualitativa en orientación educativa}

Nuestro estudio se inscribe dentro de lo que podemos Ilamar "la investigación cualitativa" que, como veremos, ha sido objeto de una gran diversidad de definiciones, perspectivas e incluso polémicas. Analizar la génesis de la investigación cualitativa supondría una tarea demasiada extensa que excede los objetivos del presente estudio, no obstante señalaremos algunas de las principales características de la investigación cualitativa, según los periodos predominantes.

- Destacamos la perspectiva histórica de Hamilton (1994) según el cual la génesis de este tipo de investigación se remonta a la aparición de las ideas kantianas, (el modelo de racionalidad humana que apuesta por la interpretación y la comprensión, la razón práctica frente a la razón científica...), en el marco filosófico del cartesianismo, (más bien la diseminación del absolutismo cartesiano).

- La perspectiva histórica de Conde (1995) que aborda la génesis de lo cualitativo a partir de lo cuantitativo centrándose en momentos y personajes cruciales de la historia entre los que destaca el descubrimiento de principios matemáticos y desarrollos científicos por Platón, Aristóteles, Newton, Heisenberg, Einstein, etc. con el entramado de transformaciones económicas, sociales, ideológicas, culturales etc. que crean las condiciones generadoras de los paradigmas.

- Otra perspectiva histórica de Vidich y Lyman (1994) es la etnografía antropológica y la sociología, que apoyados en el interaccionismo simbólico distinguen diversas fases dentro de la etnografía.

- La perspectiva cronológica de Denzin y Lincoln (1994) en la que señalan cinco grandes períodos de la investigación cualitativa en el presente siglo. 
Recogiendo las aportaciones de las diferentes perspectivas señaladas, indicamos en el Cuadro nำ 1, una síntesis de los periodos de Investigación Cualitativa

\section{Cuadro no 1: Períodos de la Investigación Cualitativa}

(Adaptado de VALLES, 1997)

\begin{tabular}{|l|l|l|}
\hline $\begin{array}{c}\text { Período } \\
\text { temporal }\end{array}$ & $\begin{array}{c}\text { Denominación del período } \\
\text { histórico }\end{array}$ & \multicolumn{1}{|c|}{ Caracterización } \\
\hline $1900-1950$ & Tradicional & $\begin{array}{l}\text { Positivismo. Preocupación por interpretaciones válidas, } \\
\text { fiables, objetivas. Época del etnógrafo solitario. } \\
\text { Predominio de la Inducción Analítica. }\end{array}$ \\
\hline $1959-1970$ & Modernista o "edad dorada" & $\begin{array}{l}\text { Postpositivismo. Formalización de los métodos } \\
\text { cualitativos, intentando encajar los argumentos de } \\
\text { Campbell y Stanley (1963) sobre la validez interna y } \\
\text { externa. Teoría fundamentada. }\end{array}$ \\
\hline $1970-1986$ & Géneros desdibujados & $\begin{array}{l}\text { Interpretación antropológica. Replanteamiento de las } \\
\text { formas de representación (escritura) y de legitimación } \\
\text { (criterios de evaluación) de las etnografias. } \\
\text { Postpositivismo y constructivismo. Los límites de las CC } \\
\text { Sociales y las Humanidades se han desdibujado }\end{array}$ \\
\hline $1986-1990$ & Crisis de representación & $\begin{array}{l}\text { Se cuestiona que el investigador haga acopio directo de la } \\
\text { experiencia vivida. Revisión de criterios caducos para } \\
\text { evaluar diseños y resultados de la investigación } \\
\text { cualitativa. Reflexividad, (auto)crítica. }\end{array}$ \\
\hline $1990-\ldots$ & Postmodernidad & $\begin{array}{l}\text { Opcionalidad de los paradigmas. Descubrimiento y } \\
\text { redescubrimiento de modos cualitativos de investigar. }\end{array}$ \\
\hline
\end{tabular}

El estudio de estos aspectos dentro de las tradiciones cualitativas reflejan los diversos niveles de análisis que se pueden considerar y que, tal como indican, (Guba y Lincoln, 1994), se pueden resumir en los siguientes, de mayor a menor nivel de interpretación, aplicando el eje de abstracción-concreción.

- Ontológico: la investigación cualitativa define la realidad, dinámica y global, como una entidad que se construye a través de procesos de interacción.

- Epistemológico: la investigación cualitativa sigue preferentemente la vía inductiva en la generación del conocimiento, y la adopción de criterios para determinar su bondad y validez. A diferencia de la vía hipotético-deductiva, en la investigación cualitativa se parte de los datos que aporta una realidad concreta para posteriormente generar teorías.

- Metodológico: Aunque existe gran diversidad en los diseños de investigación cualitativa, podemos destacar su carácter emergente de modo que el propio diseño se reelabora constantemente a lo largo de todo el proceso de investigación, manteniendo continuamente una relación dialéctica con la propia realidad, construyéndola al tiempo que extrae de ella nuevos elementos que incorporar al diseño de investigación.

- Contenido: la investigación cualitativa cruza todas las ciencias y disciplinas, de modo que podemos encontrar este tipo de investigaciones en educación, psicología, medicina, sociología, antropología, etc. 
- Técnico: la investigación cualitativa se caracteriza por el empleo de las técnicas, instrumentos y estrategias de investigación que permitan obtener información y descripciones exhaustivas sobre las situaciones peculiares y la realidad objeto de investigación.

De este modo, adoptar una investigación cualitativa, supone estudiar la realidad desde cierto conjunto de ideas (teoría), a modo de marco que va a determinar cuestiones de carácter epistemológico que acabarán guiando, (si mantenemos cierta coherencia en nuestro proceso de investigación), nuestras decisiones metodológicas. La recomendación de Denzin y Lincoln (1994) es que el investigador no pretenda ignorar cualquier paradigma, tal vez al intentar evitar definirse por un paradigma u otro, sino asimilar los supuestos ontológicos, epistemológicos y metodológicos principales estableciendo un diálogo continuo entre ellos. El supuesto "reduccionismo" al que podría conducirnos la adscripción a un determinado paradigma desaparecería si, se considera que dentro de un mismo paradigma, caracterizado por ciertos principios y supuestos generales, pueden englobarse varias perspectivas teórico-metodológicas, entendiendo por "perspectiva" los modos de estructura del paradigma, esto es, el "enfoque teórico" del paradigma.

Como conclusión, parece diáfano que la actividad investigadora más apropiada, en el ámbito de la Orientación, es el paradigma etnográfico, armonizando enfoques teóricos y metodológicos y técnicos, de índole cuantitativa y cualitativa, superando el manido y reiterativo desencuentro dicotómico irreconciliable de la medida y de la interpretación rigurosa y sistemática de la realidad.

\section{La monótona y superada dicotomía de los paradigmas cualitativo y cuantitativo}

Se ha hablado incluso de este "enfrentamiento" como elemento que ha contribuído a la definición de algunas ciencias. Así, Dávila, (1995, 73), señala que la historia de las Ciencias Sociales puede describirse como una guerra entre "explicación causal" y "comprensión estructural", entre el cuantitativismo y cualitativismo, de forma que tiende a mantenerse en tal estado, pues cada una de las partes se define por su oposición a la otra. Mientras que en la $1^{\underline{a}}$ domina el criterio lógico, (para ir de las premisas a las conclusiones basta con seguir ciertas reglas) y por tanto se preocupa de gestionar las relaciones intemporales entre las variables, en la $2^{\underline{a}}$ son los objetivos los que marcan el proceso de investigación, el mundo simbólico capturado mediante discursos que no se circunscribe a premisas previamente formalizadas para su ulterior verificación.

Por otra parte, no podemos ignorar la relación entre las posiciones teóricas y el concepto de dato, (y por tanto el de análisis de datos). Las concepciones teóricas no sólo influyen en el modo de explicar o interpretar los datos, sino que determinan qué informaciones vamos a considerar "dato". El modo de entender y utilizar el dato en la investigación educativa estará en función de nuestros presupuestos teóricos, filosóficos o de procedimientos que no hacen mas que reflejar el concepto de realidad desde el que parte la investigación: una realidad "real", lo objetivamente aprehensible, y la separación sujeto-objeto llevará a métodos centrados en el control experimental, mientras que a partir de un realismo crítico (una realidad "real" pero 
sólo imperfectamente y probabilísticamente aprehensible), que defiende la comunicación sujeto-objeto, interesarán más los métodos y técnicas cualitativos, tal como señala Guba y Lincon, (1994). Y al contrario, podríamos añadir, el tipo de "datos" que consideramos en nuestro problema de investigación, estrategias de recogida y análisis etc. ponen de manifiesto determinadas perspectivas teóricas sobre la realidad y los modos de aprehenderla-comprenderla. En el caso de la investigación cualitativa cuyo objetivo es lograr esa comprensión desde la realidad tal y como es y tal y como es interpretada por sus protagonistas, es necesario admitir que el dato no es equiparable a una información unívoca sobre un hecho o fenómeno, sino que depende de las creencias y supuestos previos desde los que son considerados. (Véase Gil Flores, 1994).

Preocupados por la conciliación entre ambos paradigmas, se sigue profundizando en las causas de dicho enfrentamiento y parece existir cierto consenso en que las diferencias fundamentales se basan en la concepción filosófica y epistemológica y no tanto en la metodológica, (Fetterman (1984), Goetz \& Lecompte (1984), Guba y Linconln (1985)). Es más, después de analizar las diferencias entre los paradigmas cuantitativo y cualitativo, (a los que Tejedor (1986) prefiere llamar racionalista y naturalista, respectivamente), se asocia la dicotomía entre los métodos cuantitativos y cualitativos al pensamiento de que existe una vinculación única e inequívoca entre método y paradigma, cuando, en realidad, no existe siempre una relación exclusiva entre método y paradigma. Para ilustrar esta afirmación cabe remitirse a algunos de los criterios que Cook y Reichardt (1979), asocian a ambos tipos de métodos. Destacamos algunos aspectos claves que suelen estar presentes en las polémicas entre cuantitativos y cualitativos:

No se pueden considerar positivistas-lógicos a todos los que utilizan métodos cuantitativos y fenomenologistas a los que utilizan métodos cualitativos ya que se pueden encontrar casos que contradicen, (falsan) esta definición. Por ej. en la perspectiva fenomenológica, la ta psicológico-social de la atribución puede investigar en un momento dado en el laboratorio usando métodos cuantitativos. Insistiendo en lo dicho, no se puede afirmar que las medidas cualitativas sean necesariamente naturalistas, ya que desde la perspectiva de la observación participante se pueden "provocar" ciertas situaciones numéricas. Y, de otra parte, podríamos añadir, (De Miguel, 1988), que incluso el uso de la cuantificación y el análisis estadístico ha sido visto como una característica de los enfoques de investigación interpretativos o cualitativos, los cuales recurren, sobre todo en el análisis de datos, a procedimientos cuantitativos típicos del enfoque positivista. En consecuencia, desde nuestra perspectiva, hay que separarse de la dicotomización radical entre lo cuantitativo y lo cualitativo, en sus distintos niveles, (epistemológico, metodológico, etc.), y buscar su complementariedad, necesaria para superar las deficiencias de uno y otro. Ortí (1995), analizando la génesis e historia de la investigación social a la luz de la confrontación entre ambos "modelos", señala que:

“(...) la realidad concreta de la investigación social nos informa una y otra vez de la insuficiencia abstracta de ambos enfoques tomados por separado. Pues los procesos de la interacción social y del comportamiento personal implican tanto aspectos simbólicos como elementos medibles (número de actores intervinientes, tamaño de los grupos, características o tipos objetivos, etc.). Mientras que el enfoque cualitativo de esos mismos fenómenos (significaciones de los discursos/sentidos de su proceso motivacio- 
nal, etc.) ni es suficiente -en cuanto se supera el nivel de las observaciones localizadas- para determinar el marco "objetivado" de su extensión o frecuencia..., ni tampoco su estatus y protocolo metodológico como modelo de análisis social llegarán nunca a satisfacer las exigencias de un modelo epistemológico autosuficiente y comparable al modelo científico-natural.(...).

Se intentará, por tanto, conciliar la lógica analítica predominante dentro del paradigma cuantitativo, (centrada en la ausencia-presencia, mayor-menor cantidad respecto a los hechos, fenómenos y relaciones objeto de investigación), con la lógica integradora cualitativa reconociendo el papel estructurante de las mediaciones simbólicas de la realidad social en la interacción personal/grupal, o mas ampliamente, en las relaciones entre distintos elementos de la realidad.

\section{Estudio de estilos de orientación}

El presente trabajo de investigación consiste en un estudio exploratorio sobre el "estilo" de Orientación de 4 Equipos Psicopedagógicos. Entendemos que este es un $1^{\text {er. }}$ paso que forma parte de un esfuerzo de investigación más amplio, en consecuencia, presentamos a continuación, los objetivos, cuestiones, y diseño de nuestro estudio, siendo conscientes de que a lo largo del proceso de investigación cualitativa pueden emerger, depurarse o eliminar algunas de las cuestiones y objetivos a medida que el contexto o los datos que se van obteniendo lo demanden.

Esto nos ha supuesto:

A. Interpretar como "Estilo", la forma habitual de actividad orientadora, condicionado por características concretas de una realidad social próxima, como pueden ser horarios de trabajo, condiciones sindicales, organización y relaciones con profesores, síntesis de condicionantes y normas legales, manera de trabajo de cada orientador, sistema aceptado de coordinación etc., que, en conjunto es la forma de especificación habitual de un Modelo Teórico de Actividad Orientadora.

B. Con el fin de aproximarnos a la realidad orientadora se han estructurado los posibles modelos de Orientación, (sin desarrollar que se entiende por "modelo", que supondría adentrarnos en matizaciones epistemológicas complejas), según tres ejes de intervención:

- Interna-Externa

- Alumno-Contexto social

- Actuación directa-Actuación indirecta

Se interpreta que, en función de todos los ejes de intervención, se especifican tres dimensiones que fundamentan cada Modelo de Orientación: (Véase Cuadro oㅜ 2)

- Bases teóricas de la interacción

- Estructura Organizativa que permite la intervención

- Desarrollo de la intervención 


\section{Cuadro nº 2: Dimensiones que fundamentan cada Modelo de Orientación}

\section{DIMENSIÓN I: Bases teóricas subyacentes a la intervención orientadora}

1. Planteamientos teóricos subyacentes a la intervención orientadora

a) explícitos, (se refleja en algún documento por escrito la teoría/s de la que se han extraído: psicoanálisis, rasgos y factores, conductismo, cognitivismo, humanismo, ecléptico...)

b) implícitos

2. Tipo de intervención orientadora en función de su finalidad:
a) terapeútica (clínica-remedial-reactiva): corregir, compensar déficits
b) prevención
c) desarrollo individual, favorecer la diversidad

3. Vinculación de la intervención orientadora con el proceso educativo (grado de implicación o interrelación entre el currículum y la Orientación)
a) mínimo
b) intermedio
c) máximo

\section{DIMENSIÓN II: Estructura Organizativa}

1. Carácter de la intervención orientadora:
a) predominantemente público, social
c) predominantemente privado

2. Ubicación de la estructura organizativa que desarrollará la intervención orientadora
a) dentro del centro educativo
b) fuera del centro educativo: zonal, sectorial, ...

3. Grado de Coordinación entre los responsables de desarrollar la intervención orientadora
a) elevado
b) medio
c) mínimo

4. Guía de la Intervención orientadora:
a) exclusivamente por funciones determinadas a priori.
b) por objetivos
c) otros

5. Sistema de análisis de necesidades
a) exclusivamente relativas al alumno
b) centradas en el alumno y su contexto: centro educativo, contexto social más amplio...
c) no existe

6. Distribución de las funciones de Orientación (y las tareas derivadas de ellas):
a) previamente delimitadas
b) emergen según las necesidades
c) otros

7. Función orientadora predominante:
a) asesoramiento
b) consulta
c) Coordinación
d) diagnóstico
e) evaluación
f) formación
g) información (transimisión de datos) 

h) investigación
i) mediación
j) detección y análisis de necesidades

\section{DIMENSIÓN III: Desarrollo de la Intervención Orientadora}

1. Unidad de intervención:
a) Individuo
b) grupo-clase
c) contexto educativo y social (programas, servicios institucionales etc...) (puede darse atención individualizada en un contexto social)

2. Destinatario/s último/s de la intervención orientadora:
a) todos los alumnos
b) exclusivamente alumnos con dificultades y de riesgo
c) otros agentes además del alumno: centro educativo, equipo docente, padres, etc...

3. Continuidad de la intervención orientadora
a) intervención puntual, única.
b) bloques de intervención discontínuos
c) contínua

4. (principal) Agente del proceso orientador
a) un profesional-experto de la Orientación incardinado en el centro educativo
b) profesor-tutor
c) sujeto orientado
d) agente externo al centro educativo
e) sistemas y/o programas autoaplicables

5. Perfil del agente de la intervención orientadora
a) especialista en Orientación, agente exterior al proceso educativo
b) especialista en Orientación, agente exterior al proceso educativo que no asesora a otros agen- tes educativos
c) especialista en Orientación implicado en el proceso educativo: ej. El orientador del centro educativo
d) educador: por ej. El profesor-tutor

6. Rol del orientador
a) consultor, asesor
b) catalizador de la acción orientadora
c) educador integrado en el equipo docente
d) técnico exterior

7. Rol del profesor-tutor
a) receptor de información o agente de $2^{\circ}$ orden (supervisado por un especialista)
b) didacta-orientador
c) consultante, intercambia información con el consultor

8. Grado de mediación, (respecto al alumno), de la intervención orientadora
a) Directa
b) Indirecta
c) Mediatizada

9. Grado de contextualización de la intevención orientadora
a) mínimo: se actua sobre el problema, no sobre el contexto

b) máximo

10. Metodología de intervención predominante de carácter:
a) individual (ej.: entrevista)
b) grupal (ej.: dinámicas de grupos) 
Para cada dimensión se ha desarrollado un cuadro de especificaciones según 6 Modelos de Orientación, (3 Básicos: Counseling, Servicios y Programas y 3 Complementarios: Servicios por Programas, Consulta y Tecnológico), señalando lo que, según nuestro criterio, es más característico en cada modelo. (Véase Cuadro no 3).

\section{Cuadro no 3: Especificaciones para cada Modelo de Orientación}

\section{Clave interpretativa}

\begin{tabular}{|l|l|}
\hline C Modelo de Counseling & S= Servicios \\
SP Modelo de Servicios por Programas & P = Programas \\
CTA Modelo de Consulta & \\
TEC Modelo Tecnológico & Rasgos con más peso en el Mod. \\
\hline \multicolumn{2}{|c|}{ Rasgos con menos peso en el Mod. } \\
\hline
\end{tabular}

DIMENSIÓN I: Bases teóricas

\begin{tabular}{|l|l|l|l|l|l|l|}
\hline 1. PLANTEAMIENTOS TEÓRICOS & C & S & SP & P & CTA & $\begin{array}{l}\text { TE } \\
\text { C }\end{array}$ \\
\hline a) explícitos & & & & & & \\
\hline b) implícitos & & & & & & \\
\hline a) TIPO DE INTERVENCIÓN & C & S & SP & P & CTA & TEC \\
\hline b) prevención & & & & & & \\
\hline c) desarrollo individual, favorecer la diversidad & & & & & & \\
\hline $\begin{array}{l}\text { 3. VINCULACIÓN ORIENTACIÓN-PROC. } \\
\text { EDUCATIVO }\end{array}$ & C & S & SP & P & CTA & TEC \\
\hline a) mínima & & & & & & \\
\hline b) intermedia & & & & & & \\
\hline c) máxima & & & & & & \\
\hline
\end{tabular}

Dimensión II:Estructura Organizativa

\begin{tabular}{|l|l|l|l|l|l|l|}
\hline 1. CARÁCTER & C & S & SP & P & CTA & TEC \\
\hline a) público, social & & & & & & \\
\hline b) privado & & & & & & \\
\hline 2. UBICACIÓN & C & S & SP & P & CTA & TEC \\
\hline a) dentro del centro & & & & & & \\
\hline b) fuera del centro (zonal,sectorial...) & & & & & & \\
\hline 3. GRADO DE COORDINACIÓN ENTRE RESPONSABLES & C & S & SP & P & CTA & TEC \\
\hline a) elevado & & & & & & \\
\hline b) intermedio & & & & & & \\
\hline c) mínimo & & & & & & \\
\hline
\end{tabular}




\begin{tabular}{|l|l|l|l|l|l|l|}
\hline 4. GUÍA DE LA INTERVENCIÓN & C & S & SP & P & CTA & TEC \\
\hline a) funciones determinadas a priori & & & & & & \\
\hline b) por objetivos & & & & & & \\
\hline c) otros & & & & & & \\
\hline 5. SISTEMAS DE ANÁLISIS DE NECESIDADES & C & S & SP & P & CTA & TEC \\
\hline a) exclusivamente relativas al alumno & & & & & & \\
\hline b) centradas en el alumno y su contexto & & & & & & \\
\hline c) no existe & & & & & & \\
\hline 6. DISTRIBUCIÓN DE FUNCIONES & C & S & SP & P & CTA & TEC \\
\hline a) previamente delimitadas & & & & & & \\
\hline b) emergen según las necesidades & & & & & & \\
\hline c) otros & & & & & & \\
\hline 7. FUNCIÓN ORIENTADORA PREDOMINANTE & C & S & SP & P & CTA & TEC \\
\hline a) asesoramiento & & & & & & \\
\hline b) consulta & & & & & & \\
\hline c) coordinación & & & & & & \\
\hline d) diagnóstico & & & & & & \\
\hline e) evaluación & & & & & & \\
\hline f) formación & & & & & \\
\hline g) información (transmisión de datos) & & & & & & \\
\hline h) investigación & & & & & & \\
\hline i) mediación & & & & & \\
\hline j) detección y análisis de necesidades & & & & \\
\hline
\end{tabular}

Dimensión III:Desarrollo de la Intervención Orientadora

\begin{tabular}{|l|l|l|l|l|l|l|}
\hline 1. UNIDAD DE INTERVENCIÓN & C & S & SP & P & CTA & TEC \\
\hline a) individuo & & & & & \\
\hline b) grupo-clase & & & & \\
\hline c) contexto ed. Y social (programas, serv. Institucionales...) & & & & & \\
\hline 2. DESTINATARIO/S ÚLTIMO/S & C & S & SP & P & CTA & TEC \\
\hline a) todos los alumnos & & & & & & \\
\hline b) exclusivamente alum. Con dificultades y de riesgo & & & & & \\
\hline c) otros agentes además del alum. (centro ed., equipo docente, padres...) & & & & & \\
\hline 3. CONTINUIDAD DE LA INTERVENCIÓN & C & S & SP & P & CTA & TEC \\
\hline a) puntual, única & & & & & & \\
\hline b) bloques de intervención discontínuos & & & & & & \\
\hline c) contínua & & & & & & \\
\hline
\end{tabular}




\begin{tabular}{|c|c|c|c|c|c|c|}
\hline 4. (PRINCIPAL) AGENTE ORIENTADOR & $\mathrm{C}$ & $\mathrm{S}$ & SP & $P$ & CTA & TEC \\
\hline \multicolumn{7}{|l|}{ a) profesional-experto incardinado en el centro ed. } \\
\hline \multicolumn{7}{|l|}{ b) profesor-tutor } \\
\hline \multicolumn{7}{|l|}{ c) sujeto orientado } \\
\hline \multicolumn{7}{|l|}{ d) agente externo al centro ed. } \\
\hline \multicolumn{7}{|l|}{ e) sistemas y/o programas autoaplicables } \\
\hline 5. PERFIL DEL AGENTE DE INTERVENCIÓN & $\mathrm{C}$ & $\mathrm{S}$ & SP & $\mathrm{P}$ & CTA & TEC \\
\hline \multicolumn{7}{|l|}{ a) especialista en Orientación, agente exterior al proc. Ed. } \\
\hline \multicolumn{7}{|c|}{$\begin{array}{l}\text { b) especialista en Orientación, agente exterior al proc. Ed. Que no asesora a } \\
\text { otros agentes educativos }\end{array}$} \\
\hline \multicolumn{7}{|c|}{ c) especialista en Orientación implicado en proc. Edu. Ej. Orientador del centro } \\
\hline \multicolumn{7}{|l|}{ d) educador ej.: el profesor-tutor } \\
\hline 6. ROL DEL ORIENTADOR & C & $\mathrm{S}$ & SP & $\mathrm{P}$ & CTA & TEC \\
\hline \multicolumn{7}{|l|}{ a) consultor, asesor } \\
\hline \multicolumn{7}{|l|}{ b) catalizador de la acción orientadora } \\
\hline \multicolumn{7}{|l|}{ c) educador integrado en el equipo docente } \\
\hline \multicolumn{7}{|l|}{ d) Técnico exterior } \\
\hline 7. ROL DEL PROFESOR-TUTOR & $\mathrm{C}$ & S & SP & $\mathrm{P}$ & CTA & TEC \\
\hline \multicolumn{7}{|l|}{ a) receptor de información 0 agente de $2^{\circ}$ orden } \\
\hline \multicolumn{7}{|l|}{ b) didacta-orientador } \\
\hline \multicolumn{7}{|l|}{ c) consultante, intercambia información con el consultor } \\
\hline 8. MEDIACIÓN RESPECTO AL ALUMNO & $\mathrm{C}$ & $\mathrm{S}$ & SP & $\mathrm{P}$ & CTA & TEC \\
\hline \multicolumn{7}{|l|}{ a) Directa } \\
\hline \multicolumn{7}{|l|}{ b) Indirecta } \\
\hline \multicolumn{7}{|l|}{ c) mediatizada } \\
\hline \multicolumn{7}{|l|}{ a) mínimo (actua sobre el problema, no sobre el contexto) } \\
\hline \multicolumn{7}{|l|}{ b) intermedio } \\
\hline \multicolumn{7}{|l|}{ c) máximo } \\
\hline 10. CARÁCTER DE LA METODOLOGÍA PREDOMINANTE & C & $\mathrm{S}$ & SP & $\mathrm{P}$ & CTA & TEC \\
\hline \multicolumn{7}{|l|}{ a) individual (ej. Entrevista) } \\
\hline b) grupal (ej. Dinámicas de grupo) & & & & & & \\
\hline
\end{tabular}

\section{Diseño del Estudio}

El diseño de investigación nos servirá para situarnos en el contexto problemático que queremos analizar y trazar las actividades iniciales que nos permitan lograr los objetivos propuestos. La selección del tipo de diseño puede venir dada según lo que Stake, (1995) denomina "oportunidad para aprender", es decir, debemos seleccionar 
aquel diseño que nos permita aprender lo más posible sobre el objeto de nuestra investigación que decidimos:

- Sea accesible,

- Sea muy probable que encontremos en él una mezcla de procesos, programas, interacciones y/o estructuras relacionadas con nuestras cuestiones de investigación, de tal modo que podamos establecer una buena relación con los informantes,

- Podamos desarrollar nuestro papel de investigadores todo el tiempo que sea necesario,

- Podamos "asegurar" la calidad y credibilidad del diseño.

Este tipo de diseños, al basarse en razonamientos inductivos permite, tal como vimos, el descubrimiento de nuevas relaciones, conceptos, significados... Sin llevar al extremo el poder del los datos recogidos en nuestra investigación para generar conocimiento, los procedimientos inductivos nos servirán para explorar ciertos supuestos teóricos que podremos modificar, redefinir, o ampliar a lo largo del proceso de investigación. (Véase el cuadro oㅡ 4 de Diseño del Estudio).

Cuadro no 4: Diseño del Estudio
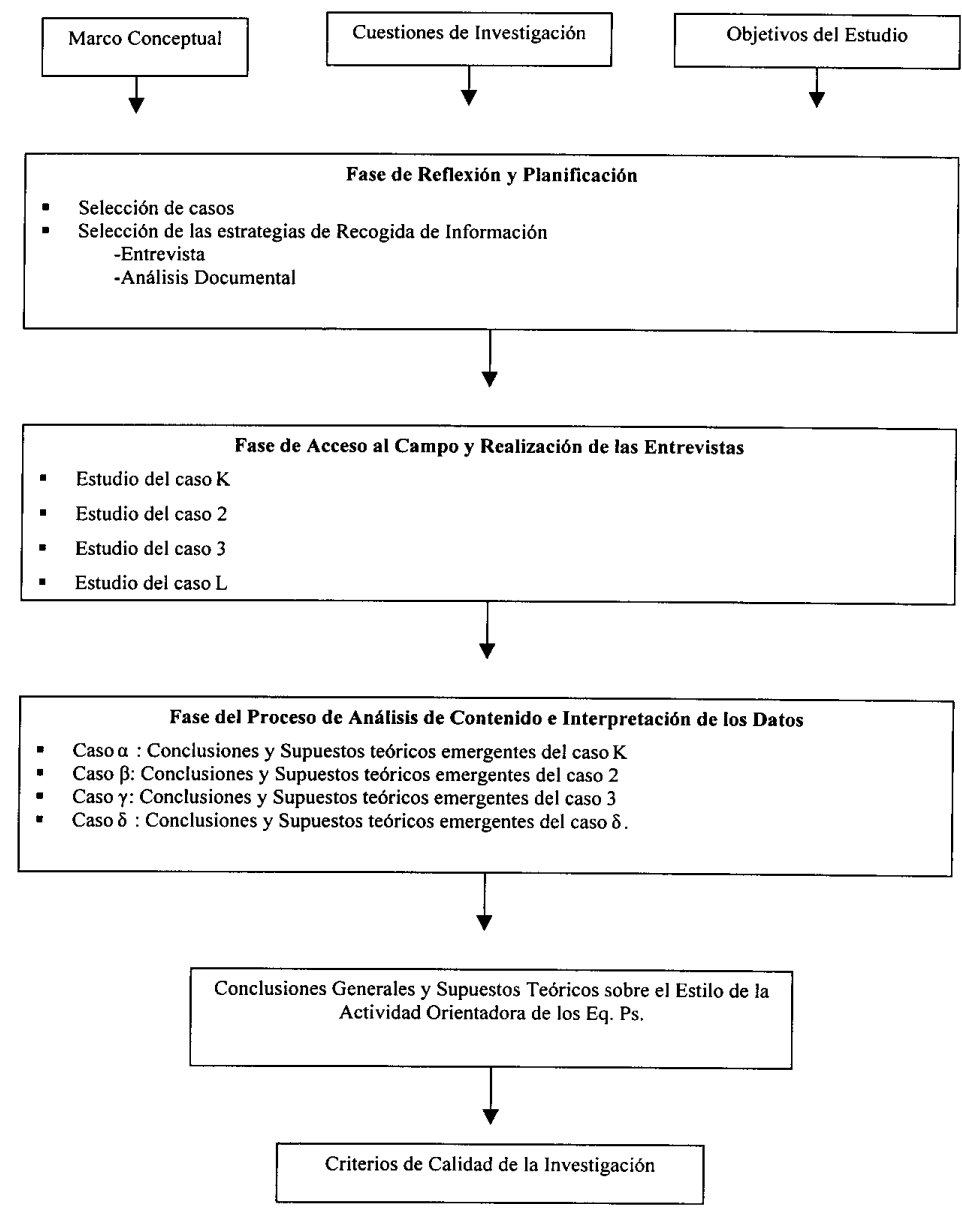


\section{Cuestiones y Objetivos del Estudio}

Las cuestiones que nos planteamos en este estudio surgen a partir de la experiencia personal de los investigadores, los contrastes con otros especialistas, el conocimiento de otros trabajos de investigación centrados en los procesos de intervención orientadora de los Equipos psicopedagógicos en diversas comunidades autónomas, (Álvarez Rojo, 1993; Escudero, J.M. 1989) y de los aspectos teóricos implicados en el concepto de "modelos de Orientación".

Inicialmente nos planteamos las cuestiones siguientes:

- ¿Cuáles son las características definitorias de la actividad orientadora, (bases teóricas, estructura organizativa, perfiles de sus agentes y protagonistas, los sistemas de planificación, la metodología, demandas orientadoras etc.), desarrollada por estos equipos?,

- ¿Cómo influyen los aspectos institucionales derivados de la estructura organizativa?

- ¿Cuáles son las justificaciones de los miembros del equipo?

Para profundizar en las cuestiones precedentes nos planteamos los objetivos siguientes:

- Describir, objetivamente y desde una perspectiva comparativa, los "modos de acción orientadora" o "estilos de Orientación" de 4 Equipos Psicopedagógicos, a partir de las percepciones, valoraciones e interpretaciones dentro de la cultura de sus miembros.

- Descubrir características de la actividad orientadora de estos equipos, conocimientos sobre su "estilo de Orientación" que pudieran permanecer latentes u "ocultos" en sus percepciones acerca del desarrollo de sus intervenciones.

- Elaborar un esquema teórico que nos ayude a comprender cuáles son los elementos, (contextuales, institucionales, teóricos, metodológicos etc.) que configuran el "estilo de Orientación" de estos equipos y cómo dichos elementos se articulan entre sí.

- Reflexionar sobre las influencias de la Ta de la Orientación, particularmente de los fundamentos teóricos sobre los modelos de Orientación, en la práctica de un grupo de profesionales de la misma, los Equipos psicopedagógicos.

- Proponer aspectos a tener en cuenta para mejorar el desarrollo de una intervención orientadora fundamentada en la reflexión teórica.

Conforme al diseño expuesto previamente, este estudio se llevó a lo largo de varias fases cuya temporalización presentamos a continuación: 


\section{Cuadro no 5: Fases en el desarrollo del estudio}

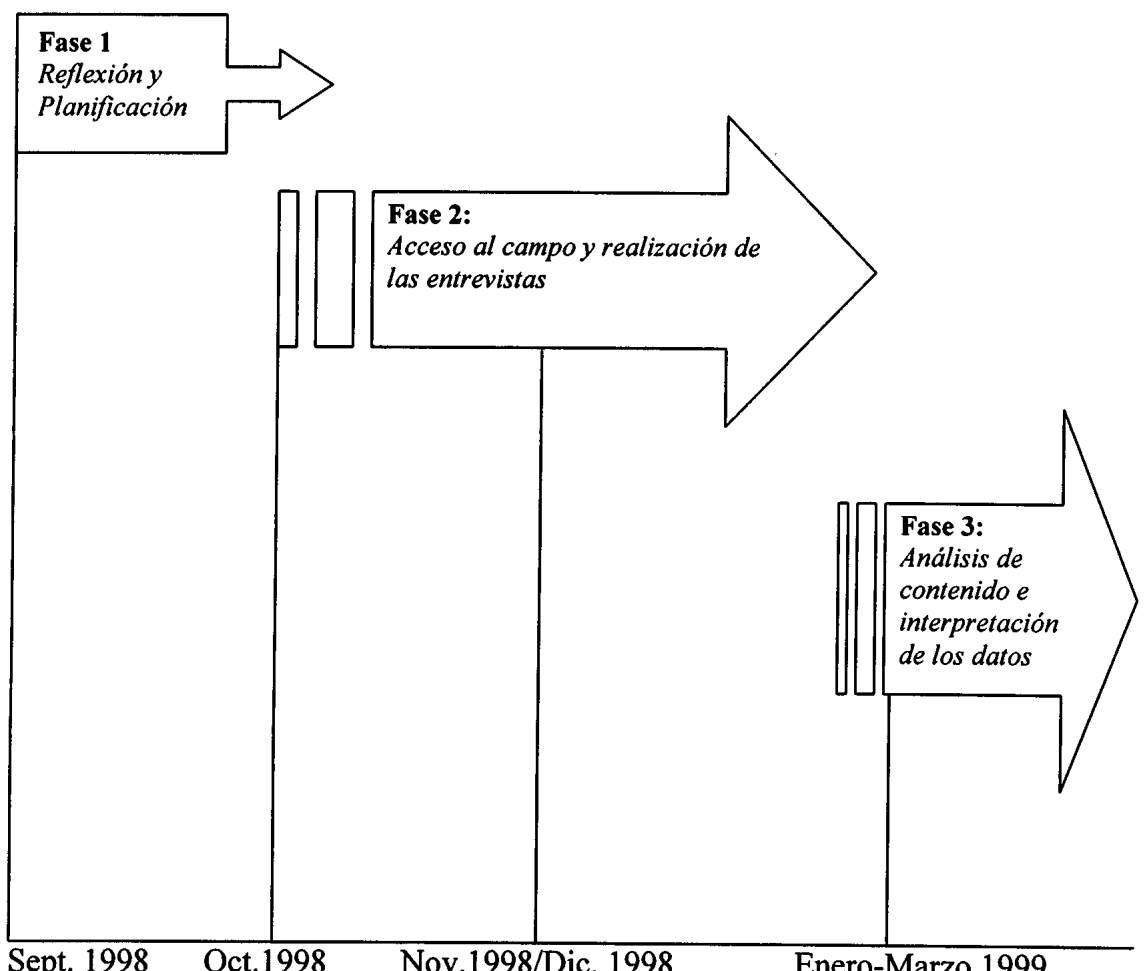

Fase de Reflexión y Planificación

Esta fase (también denominada de anticipación por Stake, 1995), debe abordar las tareas que recogemos en la secuencia siguiente:

- Investigar o descubrir que se espera al principio del estudio de casos

- Considerar los interrogantes, hipótesis, o cuestiones mas sobresalientes

- Leer acerca de algunos estudios de casos que pueden tomarse como modelos

- Identificar "el caso". ¿Fue "impuesto", seleccionado para representar algo o simplemente convenía estudiarlo?

- Definir los límites del caso (o casos) tal como se presentan.

- Anticipar los problemas clave, los sucesos, atributos, espacios, personas, señales vitales.

- Considerar las posibles audiencias para informes preliminares y finales.

- Dar forma a un plan de acción inicial, incluyendo la definición del rol del observador en el campo de estudio.

En esta fase determinamos las cuestiones y objetivos de investigación además de establecer el marco teórico-conceptual en el que transcurriría nuestro estudio, aspectos estos expuestos en apartados anteriores 


\section{Fase de Selección de Casos}

Al definir las cuestiones del estudio enfocamos nuestra atención hacia el contexto de 4 Equipos Psicopedagógicos lo cual nos pareció factible, en cuanto a condiciones de accesibilidad, posibilidades de establecer una buena relación con ellos etc. Como sucede en la mayoría de las investigaciones cualitativas, en nuestra investigación, sin renunciar completamente al rol de profesor, los investigadores adoptaron esencialmente el rol de intérprete que al mismo tiempo construye significados, ya que algunos aspectos del conocimiento se generan a partir de la reflexión interna. Como señala Stake, (1995) pueden concebirse 3 realidades,

- la 1aㅡ es externa, capaz simplemente de estimularnos,

- la $2^{a}$ realidad se refiere a las interpretaciones de esos estímulos simples, una realidad experiencial,

- la $3^{\text {a }}$ es el universo integrado de las interpretaciones, nuestra realidad racional. Estas tres realidades ejercen importantes efectos en nuestra experiencia.

\section{Fase de Recogida de Información}

La recogida de información gira en torno a una cuestión fundamental, qué datos son relevantes conforme el propósito y cuestiones de nuestro estudio. No nos detendremos aquí a estudiar el concepto y la naturaleza de los datos que pretendemos recoger, vimos como éstos dependían de los supuestos teóricos del investigador sobre la realidad y la forma de aprehenderla-comprenderla mediante los procedimientos de análisis, los cuáles han sido básicamente la entrevista y el análisis documental.

\section{Entrevista}

Nuestro interés se centraba en la comprensión de los significados de estos contenidos, valoraciones, interpretaciones, para lo cual, el contexto de interacción que genera una entrevista, en la que el investigador poco a poco va generando un clima de aceptación que favorece la libre expresión explícita y/o implícita de los entrevistados, nos parecía el más adecuado. No obstante, decidimos usar la entrevista basada en un guión, (Patton, 1990) y en la selección de informantes clave, (terminología de Goetz y Lecompte (1988)), 4 equipos psicopedagógicos, -por su acceso a la información. Así, el guión surgió a partir de la reflexión sobre las cuestiones generales de nuestro estudio, la división interna de dichas cuestiones en mini-cuestiones, a partir de las que enumeramos las ideas y tópicos que queríamos plantear en las entrevistas, basándonos en la propuesta de planificación preparación de entrevistas cualitativas de Mason (1996) que presentamos en el cuadro n⿳o 6 como especificación de cuestiones a analizar. 


\section{Cuadro no 6: Perspectiva de los procedimientos en la planificación y preparación de las entrevistas cualitativas}

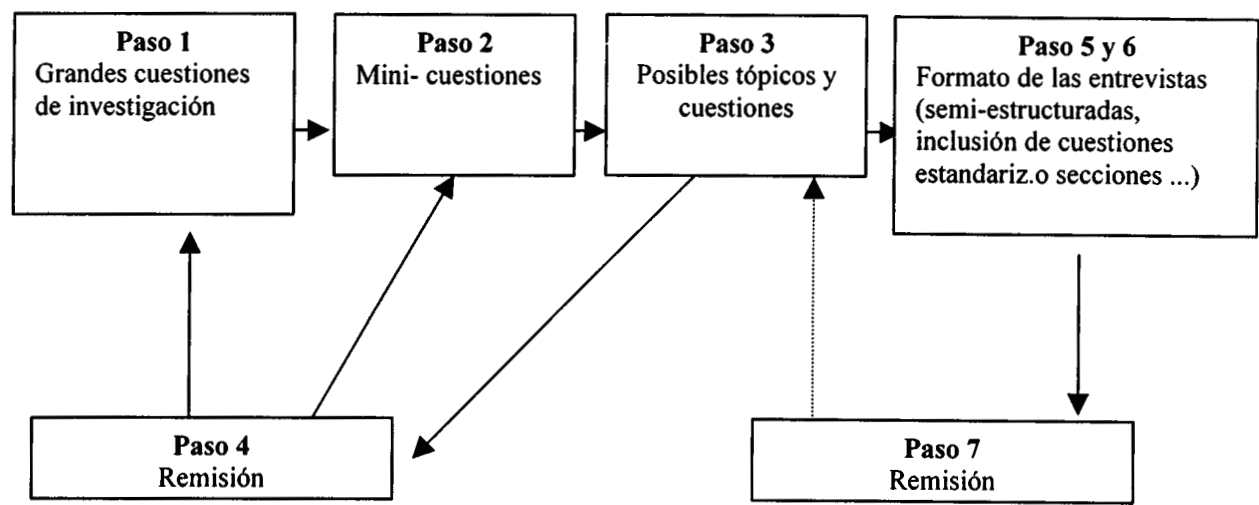

\section{Análisis de documentos}

Otra estrategia de recogida de información fue la localización de fuentes de datos acerca del contexto particular de los 4 Equipos Psicopedagógicos. Particularmente nos referimos a la Inspección Técnica de Educación, que nos proporcionó las estadísticas a partir de las cuáles describir el contexto de estos equipos y a las "Páginas Web" en las que el propio Ministerio de Educación presenta las estadísticas relativas a la población escolar, oferta educativa etc. cada curso académico. Dichos datos han resultado ser muy útiles en la descripción de ciertos aspectos "estáticos" de los Equipos de intervención Psicopedagógica, (su composición, población atendida, etc.).

\section{Fase de Acceso al Campo}

A lo largo de esta fase, en la que se incluye la recogida de datos, el investigador cualitativo deberá seguir tomando decisiones, modificando, cambiando, alterando o rediseñando su trabajo, (G. Rodríguez et al., 1996). No obstante, esta fase se define por el acceso al campo y la recogida de información, en este caso, mediante las entrevistas.

Podríamos entender el acceso al campo como un proceso a través del cual el investigador va accediendo paulatinamente a los "informantes clave", y en definitiva, a la información que precisa para profundizar en las cuestiones de investigación. En un primer momento puede suponer simplemente un permiso que hace posible la entrada a una institución o comunidad que se desea investigar. En realidad, se convierte en un proceso de negociación entre el investigador y los posibles futuros informantes. Gracias a la experiencia profesional de los investigadores, se conocían las vías "administrativas" de acceso a estos equipos, identificando desde el primer momento a los coordinadores de cada equipo como los interlocutores-clave, "porteros" en la terminología etnográfica, en la concertación de las entrevistas.

En esta fase de la investigación, hay que tener en cuenta que la presencia física del investigador no suele ser el problema principal para obtener un permiso que permita acceder al campo, (G. Rodríguez et al, 1996), sino más bien el contenido de lo que 
se desea investigar, de ahí que en realidad es un proceso que se extiende a toda la recogida de información, no sólo a los primeros contactos. Incluso en el transcurso de las entrevistas podíamos encontrarnos con que era preciso "negociar", (a través de ejemplos, aportación de la propia experiencia etc.), para obtener un nuevo tipo de información que nos parecía interesante. Así, los preliminares de las entrevistas eran utilizados por el investigador como una estrategia para "acercarse" al contexto peculiar de cada equipo. A partir de esos momentos empezaban a construirse los esquemas sociales, espaciales y temporales de la interacción entre los miembros del equipo, el entrevistador y un colaborador externo que se encargaba de las grabaciones magnetofónicas. En esta línea hemos de señalar la influencia de los "aspectos institucionales" en dicha interacción, ya que los miembros del equipo conocían la trayectoria profesional de los investigadores, que en este caso, estaba ligada también a la Administración, de ahí que fuera preciso "redefinir" continuamente "el rol del investigador en la entrevista" que en este caso no debía presentarse como inspector o "enviado de la administración" para conocer, y evaluar, tal vez podían pensar los miembros de los equipos), el funcionamiento de estos equipos.

En general, se sucedieron los mismos pasos en el desarrollo de todas las entrevistas. Los investigadores se reunían para preparar la entrevista, revisar el guión, comentar algunos aspectos emergentes en entrevistas anteriores que podía resultar interesante tratar en otras entrevistas, preparar los medios para el registro magenetofónico etc. y se desplazaban hasta la sede de los equipos. Una vez allí, transcurrían aproximadamente 45 / 60 min. en los que se desarrollaba cierto rapport entre los miembros del equipo que iban a participar en la entrevista. Durante este tiempo tenían lugar las presentaciones, en algunos casos la visita a las dependencias de la sede del equipo, etc. momentos que eran aprovechados por el investigador principal para relajar el ambiente a través de charlas informales que resolviesen dudas, aportasen cualquier información que pudiera interesarles, es decir, que facilitasen la comunicación, la expresión percepciones, ideas etc. en el transcurso de las entrevistas. A continuación, todos pasábamos a la sala donde se iba a celebrar las entrevistas cuya duración media fue de una hora aproximadamente. Finalizada la entrevista, se iniciaba nuevamente una fase de despedida en la que se les agradecía su colaboración y se les indicaba que se contactaría con ellos más adelante para darles a conocer las transcripciones de las entrevistas y ver su grado de acuerdo con ellas, de modo que pudiesen introducir cualquier tipo de corrección o sugerencia que considerasen pertinente durante un periodo de 20 días aproximadamente.

Realizadas las transcripciones de las entrevistas, se enviaron a cada uno de los equipos junto con unas primeras interpretaciones de los rasgos más destacados, sin embargo, sólo dos de los equipos acusaron su recibo y contestaron por carta dando total conformidad con cuanto había en las transcripciones. Tras nuevos contactos con los equipos para ver la necesidad de introducir nuevos aspectos a analizar en las entrevistas, modificar algunas interpretaciones etc. nos encontramos en un $90 \%$ de los casos con la total aceptación de lo expuesto, sin que considerasen necesario introducir ninguna modificación. Se incluye a continuación la ficha descriptiva realizada en cada caso. (Ver Cuadro $\mathrm{n}^{\mathrm{o}}$ 7). 


\section{Cuadro no 7: Ficha Descriptiva de las entrevistas}

\begin{tabular}{|c|c|}
\hline ENTREVISTA $\mathrm{N}^{\circ}$ & EQ. $\mathrm{N}_{-}^{\circ}$ \\
\hline FECHA: & \multirow{3}{*}{ min. } \\
\hline DURACIÓN APROXIMADA: & \\
\hline ENTREVISTADOR: & \\
\hline IDENTIFICACIÓN DE LOS M & IEMBROS DEL EQUIPO: \\
\hline$-A:$ & \\
\hline$-B:$ & \\
\hline$-\mathrm{C}:$ & \\
\hline$-\mathrm{D}:$ & \\
\hline$-E:$ & \\
\hline
\end{tabular}

Análisis de Contenido e Interpretación de los Datos

Debemos aclarar que hemos considerado el análisis e interpretación de los datos separados de la fase anterior, (recogida de información), para facilitar la exposición del proceso de investigación. No obstante, rechazamos al igual que otros investigadores, (Gil Flores, 1994; Miles y Huberman (1994)), que estas fases puedan considerarse como entidades separadas, ya que ello excluiría la posibilidad de recoger nuevos datos para rellenar huecos o comprobar nuevas hipótesis que surgen a lo largo del estudio. Paralelamente, hemos reunido el análisis y la interpretación de los datos bajo un mismo epígrafe, siguiendo a autores como Erickson, (1989), cuando afirma que el análisis de los datos está presente también en la fase de elaboración de informes, pues el propio estilo literario que emplea el investigador para dar sentido a los datos, supone un conocimiento más profundo de los mismos y otros, como Goetz y Lecompte (1988), para los que la interpretación supone profundizar en la cultura e interpretaciones de los participantes lo que revierte en una redefinición de las cuestiones de investigación.

Hay muchas definiciones sobre análisis de datos, por escoger una particularmente concreta y clarificadora, podríamos señalar la de Miles y Huberman, (1994): el análisis de datos abarca un conjunto de actividades tendentes a reducir los datos a unidades manejables y significativas, estructurar y presentar los datos y extraer conclusiones que avancen en la comprensión del todo. En esta ocasión hemos elegido el análisis de contenido con el fín de descubrir los componentes básicos, (percepciones positivas, negativas, necesidades, fundamentos teóricos etc...) de la actividad orientadora de los equipos a partir del contenido de sus declaraciones.

De este modo, intentaramoss analizar las formas de expresividad oral que tuvieron lugar en el transcurso de las entrevistas con los Equipos Psicopedagógicos denominados $\alpha, \beta, \gamma, \delta$, manteniendo su anonimato y referencia y contexto, pero dado que estos 
análisis se realizarán a partir de las transcripciones escritas de las mismas, en realidad estamos trabajando sobre textos. Así, el dominio de nuestro análisis de contenido será el de las expresiones verbales que pueden ser objeto de investigación tanto de las técnicas textuales como del análisis de contenido, sin olvidar que el papel tanto de la instrumentación como de la cuantificación dentro de la etnografía es el de "reforzar" ciertos datos e interpretaciones.

En aquellos casos en los que la cuantificación se convierte en el aspecto central del análisis, recurriendo a la cuantificación de los textos desde el primer momento sin intervenciones previas del investigador, nos encontramos en la línea de los enfoques lexicométricos, que llevan a cabo diversos análisis estadísticos de datos textuales especialmente enriquecidos con técnicas como el análisis de correspondencias o la clasificación automática, desarrolladas a partir de las aportaciones de Benzécri, (1973). En partircular, el análisis de contenido que realizamos con el programa SPADT nos permitirá profundizar en los contenidos manifiestos, las estructuras latentes, que pudieran hallarse en la entrevista, puesto que, al no tratarse de textos muy largos, la simple extracción de temas, (el análisis exclusivo del contenido manifiesto), no necesitaría de los análisis que vamos a realizar.

Como herramienta informática hemos elegido el programa SPAD-T -Systéme Portable pour l'Analyse des Donneés Textuelles- (Lebart, Morineau y Bécue, 1991), debido a su accesibilidad, adecuación a los datos y a los propósitos de nuestra investigación. Mediante un sistema interactivo, este programa nos permitirá elaborar los documentos lexicométricos que servirán de base al análisis de datos, así como establecer la cadena de procedimientos necesarios para llevar a cabo los distintos análisis. En consecuecia, emplearemos tanto técnicas paradigmáticas, como la extracción de formas características en los textos, basadas en su frecuencia de aparición, porque dichas formas resultan fácilmente identificables y permiten una segmentación del texto inequívocamente delimitada, (Etxeberría et al, 1995). Al mismo tiempo, utilizaremos técnicas sintagmáticas, como la extracción de segmentos, interesadas por el contexto en que se emplean dichas formas, para evitar la posible descontextualización y/o ambigüedad de palabras aisladas. A continuación, reflejamos en el cuadro $n^{\circ} 8$ los pasos seguidos en el proceso de análisis de contenido paralelamente a los procedimientos informáticos disponibles en el SPAD-T, para llevarlos a cabo.

Las transcripciones fueron segmentadas finalmente en 13 categorías generales establecidas (Cuadro no 9). Aunque en la mayoría de los casos podríamos señalar varias categorías generales asociadas a una misma frase, hemos realizado adscripciones excluyentes, decidiéndonos por el tópico al que más referencia hacía dicha frase o párrafo, debido a las características específicas del programa SPAD-T, que vamos a usar a continuación. Por lo tanto, de esta primera segmentación referida a las categorías generales, sólo pretendemos extraer una visión de conjunto que nos ayude a matizar e interpretar los resultados que obtendremos posteriormente al aplicar otras técnicas más sistemáticas. 


\section{Cuadro no 8: Proceso de Análisis de Contenido}

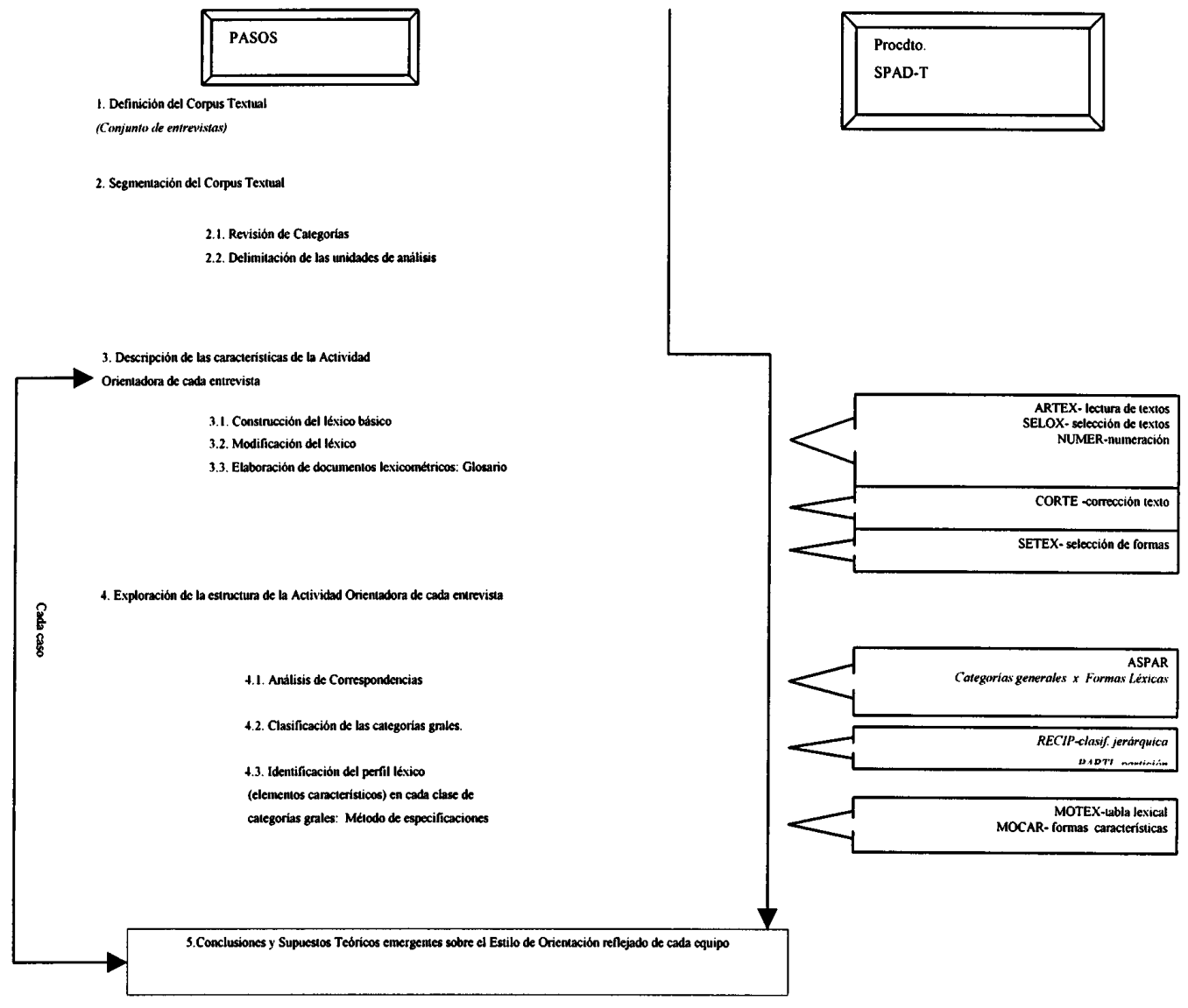

Siguiendo el proceso se realizaron los pasos siguientes:

\section{Definición del Corpus textual}

Nuestro corpus textual, es decir, los textos que en un momento dado son objeto del análisis de contenido, está constituido en una 1 $1^{a}$ parte del proceso, (pasos del 3 al 5 ), por cada una de las entrevistas, (casos), tomadas por separado y en una $2^{\mathrm{a}}$ parte del proceso (paso 6), por las entrevistas consideradas globalmente.

\section{Segmentación del Corpus Textual}

\section{Revisión de Categorías}

Una vez leídas las transcripciones de las entrevistas nos hemos hecho ciertas ideas globales sobre las mismas, que nuevamente llevan al investigador a redefinir a partir de la práctica y revisar los tópicos o categorías generales que utilizó como guión para conducir las entrevistas. De este modo, los tópicos señalados en la fase de planificación, quedarían reducidos a 13. (Véase cuadro no 9) tras:

- reunir los tópicos referidos a procedimientos de Orientación y asesoramiento utilizados con más frecuencia, los instrumentos utilizados habitualmente descrip- 
ción del tipo de entrevistas llevadas a cabo por los miembros del equipo y dinámicas grupales, tipos y actividades, todo ello en una misma categoría denominada "Procedimientos, instrumentos, técnicas de Orientación y Asesoramiento", ya que los miembros de los equipos no parecían apreciar diferencias importantes en relación al contenido de esos cuatro tópicos inicialmente señalados por el investigador.

- reunir los tópicos sobre actividades de participación de los orientadores en los Claustros, e incardinación real del equipo con otras instancias educativas en una única categoría general denominada "Relación con otras instancias educativas: MEC, centros educativos etc.

Como consecuencia, serán 13 las categorías generales utilizardas a partir de ahora para describir el estilo de Orientación de estos 4 Equipos Psicopedagógicos.

\section{Cuadro no 9: Categorías Generales en el Proceso de Análisis de Contenido}

\section{Sistemas de Planificación}

2. Programas de Orientación

3. Sistema de análisis de necesidades

4. Estructura de funcionamiento del equipo

5. Periodicidad en la coordinación

6. Distribución de las tareas (quién hace qué).

7. Relación con otras instancias educativas.

8. Temas/Problemas atendidos con más frecuencia

9. Procedimientos, instrumentos, técnicas de Orientación y asesoramiento

10. Seguimiento, evaluación y realización de informes, (tanto del propio equipo como de la administración y referidos tanto a los alumnos como a las actividades de Orientación realizadas por los miembros del equipo).

11. Satisfacción en los destinatarios.

12. Satisfacción en los orientadores.

13. Estilo de Orientación.

\section{Delimitación de las unidades de análisis de contenido}

La segmentación del corpus textual es un proceso por el que dividimos los datos textuales en diversos tipos de unidades conforme a determinados criterios que deben establecerse a partir de las características de los textos y los objetivos del análisis, esto es, según el nivel/es en los que vayamos a desarrollar el análisis de contenido, (sintáctico, semántico, pragmático).

Señalamos a continuación los tipos de unidades que distinguimos en nuestro estudio:

- Unidades de muestreo: las entrevistas realizadas a los Equipos Psicopedagógicos a, $B, y d$.

- Unidades de registro: inicialmente tomamos las palabras-clave, establecidas a partir de un criterio semántico. Sin embargo, esta 1a primera estructuración del 
texto no es más que el punto de partida para el núcleo de nuestro análisis de contenido, llevado a cabo mediante el programa SPAD-T. Cuando utilizamos este programa tomamos como unidades de registro las denominadas formas gráficas, que son unidades físicas, fácilmente reconocibles por el ordenador que permiten por tanto una segmentación automática (Etxeberría et al. 1995), a diferencia de lo que ocurre cuando segmentamos el texto en función de la unidad temática y los segmentos repetidos, éstos como unidades de registro en la última parte de nuestros análisis en la que consideramos conjuntamente todas las entrevistas.

Así, adoptaremos la definición de forma gráfica de Lebart y Salem, (1988), entendidas como la secuencia de caracteres no delimitadores, (generalmente letras), comprendida entre dos caracteres delimitadores, (espacios o signos de puntuación), y la definición de segmentos repetidos como la secuencia de dos o más palabras, no separadas por un delimitador de secuencia, ("delimitador fuerte"), que aparecen más de una vez en el conjunto de los textos estudiados.

- Unidades de contexto para interpretar las unidades de registro. En la primera segmentación del texto, en la que tomábamos como unidades de registro las palabras-clave referidas a nuestras categorías generales, tomaremos como unidad de contexto cada una de las entrevistas, ya que dentro de ellas, es donde adquieren sentido las unidades de registro. Sin embargo, cuando los procedimientos de análisis del SPAD-T consideren como unidades de registro las formas gráficas, para nosotros, las unidades de contexto serán las frases, en función de las cuáles podremos interpretar adecuadamente las formas gráficas.

Una vez que hemos definido el corpus textual y segmentado el texto, pasamos a describir, en cada uno de los casos, las características de la Actividad Orientadora mediante el análisis del léxico básico, esto es, el análisis de los documentos lexicográficos elaborados a partir del vocabulario de las entrevistas, la clasificación de este vocabulario tomando como referencia las categorías ya indicadas y la aplicación del método de especificaciones que señalará cuáles son los términos característicos de cada frase, (su perfil léxico).

A continuación presentaremos los principales elementos resultantes de estos análisis, tanto los procedimientos del SPAD-T que hemos aplicado para llevarlos a cabo como los criterios que hemos seguido en la selección de términos o en el establecimiento de las clases, (sólo señalamos un ejemplo de CASO B véase el cuadro no 10$)$.

Para estudiar la forma particular que adopta la clasificación de las categorías generales que propusimos anteriormente, llevamos a cabo un análisis de correspondencias, para asociar, (Benzécri, 1973), las categorías generales y los términos que constituyen nuestro léxico. De manera que esta técnica se aplica sobre una tabla léxica que, en el CASO B tenía por filas las 13 categorías generales y por columnas las 25 formas léxicas seleccionadas, ofreciéndonos las coordenadas factoriales de cada categoría general que el programa SPAD-T retiene como punto de partida para clasificar, dichas categorías en clases homogéneas en función del vocabulario asociado a ellas. 


\section{Cuadro no 10 : Glosario definitivo de palabras retenidas (CASO b)}

\begin{tabular}{|l|l|l|l|}
\hline NUM. & PALABRAS EMPLEADAS & FRECUENCIA & LONGITUD \\
\hline 1. & Administración & 9 & 14 \\
2. & Algo & 10 & 4 \\
3. & Centro & 10 & 6 \\
4. & Cosa & 10 & 4 \\
5. & Cuando & 11 & 6 \\
6. & Decir & 9 & 5 \\
7. & Equipo & 9 & 6 \\
8. & Esta & 11 & 4 \\
9. & Estamos & 6 & 7 \\
10 & Este & 8 & 4 \\
11 & Hace & 6 & 4 \\
12 & Hacer & 10 & 5 \\
13 & Hemos & 7 & 5 \\
14 & Menos & 6 & 5 \\
15 & Mucho & 6 & 5 \\
16 & Nosotros & 20 & 8 \\
17 & Otro & 11 & 4 \\
18 & Para & 13 & 4 \\
19 & Porque & 14 & 6 \\
20 & Problema & 11 & 8 \\
21 & Programa & 9 & 8 \\
22 & Programas & 9 & 9 \\
23 & Tipo & 7 & 4 \\
24 & Todo & 16 & 4 \\
25 & trabajo & 6 & 7 \\
\hline
\end{tabular}

Una vez que el SPAD-T presentaba diversos agrupamientos entre las categorías generales, explorábamos el árbol resultante de distintas particiones, y para determinar la clasificación de categorías generales seguíamos el criterio de cortar el dendograma en el nivel donde se produce un salto considerable en la pérdida de inercia interclases entre dos nudos consecutivos. Así, obtuvimos las diversas clasificaciones para cada caso tal como se expone, como ejemplo en el cuadro $n^{0} 11$ correspondiente al Equipo B.

\section{Cuadro no 11: Partición obtenida tras el corte transversal del dendograma del Equipo $B$}

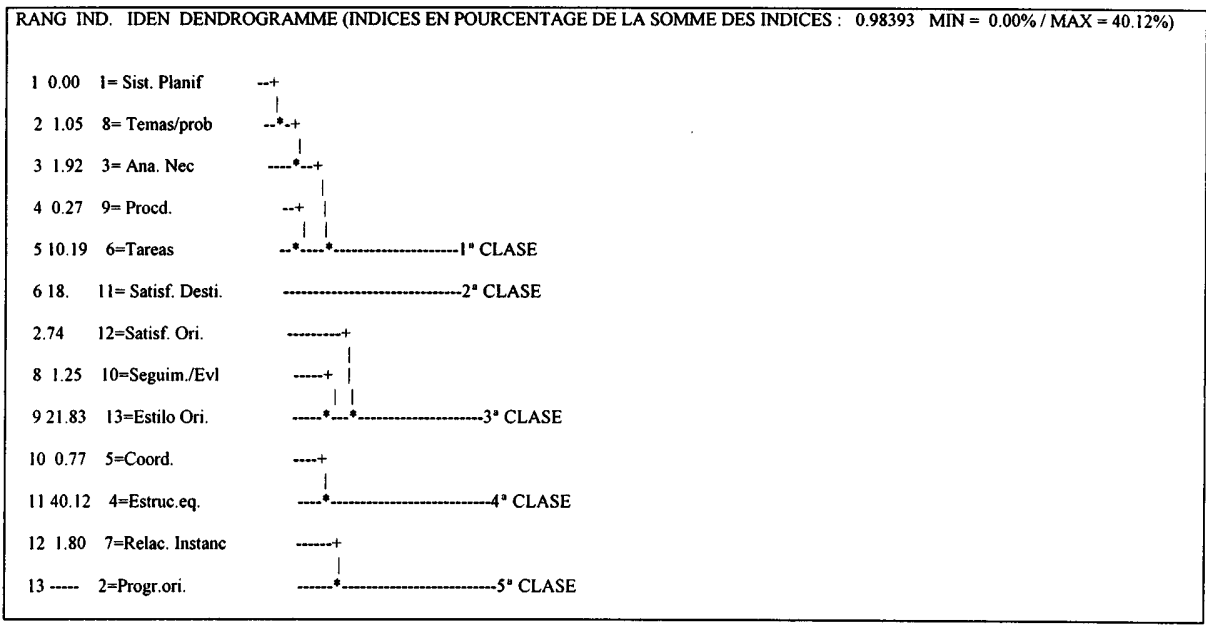


Una vez terminadas las clases de categorías generales que habíamos distinguido en cada caso, calculamos mediante el método de especificaciones las formas léxicas específicamente positivas y negativas en cada una de las clases, esto es, aquellos términos sobreutilizados e infrautilizados en ellas, respecto a la frecuencia con que eran empleadas en el resto.

\section{Conclusiones}

Tras estudiar los términos característicos de cada clase y las relaciones semánticas con las categorías que la definían, extrajimos algunas conclusiones y supuestos teóricos derivados del proceso de análisis de cada caso, especificando conclusiones del estilo especial de intervención, cruce de los realizado, pretendido y conseguido en cada modelo de Orientación, que, según nuestro criterio, es la concreción orientadora de las actividades, lo que denominamos Estilo de Orientación de cada Equipo Orientador.

En general, los investigadores han podido apreciar en el desarrollo del estudio que existen muchos rasgos comunes en el estilo de la actividad orientadora de todos los equipos analizados. Tal vez el más sobresaliente es la aparente ausencia de un modelo teórico de Orientación definido que guíe de alguna manera sus intervenciones. Globalmente podríamos decir que el estilo de su actividad orientadora está más próximo a lo que se conoce como modelo de servicios, (en realidad más que un modelo se trataría de una organización institucional determinada, a partir de la que se configuran sus intervenciones), que al modelo de programas. Ello no es de extrañar, si consideramos que, respecto a las bases teóricas que fundamentan sus intervenciones, a lo largo de los análisis pudimos apreciar que los equipos tenían dificultades para conceptualizar la expresión de "programas de Orientación", o bien la identificaban, con algo genérico, con la planificación y/o programación de actividades de Orientación específicas para responder a ciertas demandas orientadoras por parte de los profesores-tutores. Parecían suponer que un requisito previo imprescindible para poder desarrollar estos programas era contar con la confianza de los centros, para lo cuál debía transcurrir cierto tiempo de relaciones de colaboración y trabajo eficaz.

Paralelamente, no parece que existan sistemas establecidos ni de planificación ni de análisis de necesidades, sino más bién, lo que se denomina el plan de trabajo, que se establece paulatinamente apoyándose básicamente en las directrices dadas por la administración modificadas en función de las necesidades prioritarias de Orientación que deben atender en un momento dado. Por ello no es de extrañar que a menudo apreciásemos en los resultados de los análisis ciertas relaciones entre el estilo de Orientación, y los análisis de necesidades. En función de esas necesidades, de los problemas a atender, parecen distribuirse administrativamente las tareas de Orientación, los casos a atender, sin tener en cuenta la especialización profesional de cada miembro del equipo. Este tipo de interacciones, junto con algunas otras de carácter general para acordar criterios comunes de actuación, son las que suelen realizarse semanalmente en la sede de los equipos. No obstante, parece existir cierto sentido de grupo entre ellos, (tal vez acentuado por las características de la entrevista que sirvió de base para recoger sus interpretaciones, realizada como un equipo frente a los investigadores), que parece estar bastante influido por la composición peculiar del grupo, (las especialidades pro- 
fesionales de sus miembros y su procedencia: SOEV o Equipos Multidisciplinares de Sector) y los años de permanencia en el equipo.

Las tareas de Orientación parecen centrarse en el diagnóstico, la evaluación, el seguimiento y la elaboración de documentos informativos de manera que parecen predominar las intervenciones puntuales, individuales sobre todo, (con carácter remedial, terapeútico), como respuesta a las necesidades detectadas por los profesorestutores y transmitidas al equipo mediante el jefe de estudios.

Respecto a la satisfacción de los destinatarios de su acción orientadora, hemos encontrado cierta confusión en su definición, (etiquetado como algo, bastante, más satisfechos que antes...), aunque, en general, no dudan al interpretar las expectativas que los centros, profesores y familias tienen sobre ellos, esto es, todos están de acuerdo en que desean que los equipos psicopedagógicos les resuelvan los problemas. Ninguno sugiere la posibilidad de intervenir para introducir innovaciones como iniciativa de los centros, sino más bien que una vez cumplida la función de resolver los problemas y crear relaciones de colaboración amistosas con los profesores, directores, etc. podrían intentar asumir otro tipo de funciones de mayor carácter preventivo y de desarrollo. De hecho, destacan en todos los casos, los esfuerzos realizados por los miembros de estos equipos por colaborar y "llevarse bien" con los destinatarios de su actividad orientadora, de modo que los indicadores de satisfacción tanto en los propios miembros del equipo como en sus destinatarios suelen ser el clima predominante en estas relaciones y la continuidad de demanda orientadora.

Finalmente, cabe destacar que todos ellos se encuentran satisfechos en mayor o menor grado con su actividad orientadora, que además de basarse en el trabajo eficaz, (resolución de problemas), y las relaciones personales, parece apoyarse en su propia estructura de funcionamiento, de manera que no parecen percibir necesidad alguna de cambiarla.

\section{Propuesta de Futuros Análisis}

El presente estudio podría continuarse mediante el contraste de un Sistema de Categorías sobre los Modelos de Orientación elaborado a partir de la teoría y modificado a partir de la información obtenida en este primer estudio, en una investigación dirigida a determinar el Modelo de Orientación seguido por los Equipos Psicopedagógicos. En esta ocasión se trataría, no de describir tal cual la realidad, sino de contrastar dicha realidad, esto es las características de la actividad orientadora de los equipos, tomando como referencia un sistema de categorías en el que cada dimensión y los elementos dentro de ella, adquieren un peso específico en la definición de cada uno de los Modelos de Orientación. 


\section{Bibliografía}

ÁlVAREZ ROJO, V. (1993). Proyecto docente e investigador. Sevilla: Universidad de Sevilla.

ÁLVAREZ ROJO, V. (1994). Orientación educativa y acción orientadora. Madrid: EOS. BENZÉCRI, J.P. (1973). L'Analyse des Données. París: Dunod.

CAMPBELL, D. y STANLEY, J. (1963). Experimental and quasi-experimental designs for research on teaching. En N. Gage (Ed.), Handbook for research on teaching, (pp. 171-246). Chicago: Rand McNally.

CONDE, F. (1995). Las perspectivas metodológicas cualitativa y cuantitativa en el contexto de la historia de las ciencias. En J.M. Delgado y J. Gutiérrez (Coord.), Métodos y Técnicas cualitativas de investigación en ciencias sociales, (pp. 53-68). Madrid: Síntesis.

COOK, T.D. y REICHARDT, C.S. (Eds).(1986). Métodos cualitativos y cuantitativos en investigación evaluativa. Madrid: Morata.

DÁVILA, A. (1995). Las perspectivas metodológicas cualitativa y cuantitativa en las ciencias sociales: debate teórico e implicaciones praxeológicas. En J.M. Delgado y J. Gutiérrez (Coord.), Métodos y Técnicas cualitativas de investigación en ciencias sociales, (pp. 69-83). Madrid: Síntesis.

DE MIGUEL, M. (1988). Paradigmas de la Investigación Educativa Española. En I. Dendaluce (Coord.), Aspectos metodológicos de la Investigación Educativa, II Congreso Mundial Vasco. (pp. 60-77). Madrid: Narcea.

DENZIN, N.K. y LINCOLN, Y.S. (Eds.) (1994). Handbook of qualitative research. Londres: Sage.

ERICKSON, F. (1989). Métodos cualitativos de investigación sobre la enseñanza. En M.C. Wittrock, (Ed.), La investigación de la enseñanza, (pp. 125-131). Madrid: Paidós-MEC.

ESCUDERO, J.M. (1989). Evaluación de los equipos psicopedagógicos de la Comunidad de Madrid. Madrid: C.A.M.

ETXEBERRÍA, J., GARCÍA, E., GIL FLORES, J. y RODRÍGUEZ, G. (1995). Análisis de datos y textos. Madrid: Ra-Ma.

FETERMAN, D.M. (1984). Etnography in educational evaluation. Newbury Park, Ca: Sage.

GIL FLORES, J. (1994). Análisis de datos cualitativos. (Aplicaciones a la investigación educativa). Barcelona: PPU.

GOETZ, J. \& LECOMPTE, M. (1984). Etnography and qualitative design in educational research. Orlando: Academic Press.

GOETZ, J. \& LECOMPTE, M. (1988). Etnografía y diseño cualitativo en investigación educativa. Madrid: Morata.

GUBA, E.G. y LINCOLN, Y.S. (1994). Competing Paradigms in Qualitative Research. En N.K. Denzin e Y.S. Lincoln (Eds.), Handbook of Qualitative Research, (pp. 105117). Thousands Oaks, CA: Sage Publications. 
HAMILTON, D. (1994). Traditions, preferences, and postures in applied qualitative research. En N. K. Denzin \& Y. Lincoln (Eds.), Handbook of qualitative research, (pp. 60-69). Thousand Oaks, Ca.: Sage.

HERR, E.L. y CRAMER, S.H. (1988). Career guidance and counseling through the life span. Systematic approaches. Illinois: Scott-Foresman.

LÁZARO, A. (1978): (Coord.) : El Equipo Orientador, Bordón. 222, (monográfico).

LEBART, L. y SALEM, A. (1988). Analyse Statistique des Données textuelles. Questions ouvertes et Lexicométrie. París: Bordas.

LEBART, I., MORINEAU, A. y BECUE, M. (1991). SPAD-T. Systéme portable pour I'analyse des données textuelles. Manuel d I'utillisateur. Paris: CISIA.

LECOMPTE, M. (1995). Un matrimonio conveniente: diseño de investigación cualitativa y estándares para la evaluación de programa. Revista electrónica de Investigación y Evaluación Educativa, 1 (1).

LECOMPTE, et al (1992). Qualitative research in education. London: Academic Press.

LEVINSON, D.J., DARROW, C.N., LEIN, E.B., LEVINSON, S.H. y MCKEE, B. (1978). The seasons of a man's life. New York: Randon House.

LOFLAND, J. y LOFLAND, L.H. (1971/1984). Analyzing social settings: a guide to qualitative observation and analysis. Belmont, CA: Wadsworth.

MASON, J. (1996): Qualitative Researching. London: Sage.

MILES, M.B. y HUBERMAN, A.M. (1994). Qualitative Data Analysis: a sourcebook of new methods, ( $2^{\mathrm{a}}$ ed.). Thousand Oaks, Ca.: Sage.

ORTÍ, A. (1995). La confrontación de modelos y niveles epistemológicos en la génesis e historia de la investigación social. En En J.M. Delgado y J. Gutiérrez (Coord.), Métodos y Técnicas cualitativas de investigación en ciencias sociales, (pp. 85-95). Madrid: Síntesis.

PATTON, M.Q. (1990). Qualitative Evaluation and Research Methods. London: Sage.

RODRÍGUEZ GÓMEZ, G., GIL FLORES, J. y GARCÍA JIMÉNEZ, E. (1996). Metodología de la investigación cualitativa. Málaga: Aljibe.

STAKE, R. (1995). The art of Case Study Research. Thousand Oaks, CA: Sage

TEJEDOR, F.J. (1986). La estadística y los diferentes paradigmas de investigación educativa. Educar, 10, 79-101.

VALLES, M.S. (1997). Técnicas cualitativas de investigación social (reflexión metodológica y práctica profesional). Madrid: Síntesis.

VIDICH, A.J. y LYMAN, S.M. (1994). Qualitative methods: their history in sociology and anthropology. En N.K. Denzin \& Y. Lincoln (Eds.) Handbook of qualitative research, (pp. 23-59). Thousand Oaks, Ca.: Sage.

WEBER, R.P. (1985). Basic Content analysis. Beverly Hills: Sage.

WEITZMAN, E.A. \& MILES, M.B. (1995). Computer programs for qualiative data analysis. London: Sage. 